\title{
LA PARTICIPACIÓN DE LA VÍCTIMA EN LA PERSECUCIÓN PENAL OFICIAL. ANÁlISIS A PARTIR DE LA JURISPRUDENCIA Del TRIBunal CONSTITUCiOnal ${ }^{*}$
}

\author{
Daniela Aguilera BertucC ${ }^{* *}$
}

RESUMEN: El presente artículo trata el problema de la participación de la víctima en el proceso penal chileno. Su planteamiento central dice relación con la importancia de adecuar la intervención del ofendido a la naturaleza oficial del procedimiento penal, postulándose que este debe cumplir un rol de control respecto de la persecución penal estatal. Se da cuenta de ciertas dificultades que presentan las normas constitucionales y legales que regulan el proceso penal para efectos de esta diferenciación de roles. El análisis se realiza a partir de los problemas planteados ante el Tribunal Constitucional, considera su jurisprudencia en la materia, así como planteamientos de doctrina procesal penal chilena y extranjera.

PALABRAS CLAVE: Proceso penal - Ministerio Público - víctima principio de oficialidad - Tribunal Constitucional.

\section{PARTICIPATION OF THE VICTIM IN THE OFFICIAL CRIMINAL PROSECUTION. ANALYSIS FROM THE CONSTITUTIONAL COURT JURISPRUDENCE}

ABSTRACT: This article addresses the issue of victim participation in criminal proceedings in Chile. Its central approach is related to the importance of adapting the intervention of the offended to the official nature of the criminal proceedings, claiming that it must play a role of control with respect to state criminal prosecution. It realizes the difficulties that present constitutional and legal rules governing criminal proceedings for the purposes of this differentiation of roles. The analysis is based on the issues raised before the Constitutional Court, it considers

* Este trabajo se ha realizado en el marco y con financiamiento del proyecto Fondecyt $\mathrm{n}^{\mathrm{o}}$ 1100362 sobre "La acción penal", cuyo investigador responsable es Andrés Bordalí Salamanca.

** Licenciada en ciencias jurídicas, alumna del Magíster en Derecho de la Universidad Austral de Chile, programa en que se ha desarrollado este trabajo. Correo electrónico: daniela.aguilera@postgrado.uach.cl

Fecha de recepción: 31 de julio de 2011.

Fecha de aceptación: 22 de septiembre de 2011. 
the case law and doctrine approaches of the chilean and foreign criminal procedures.

KEY WORDS: Criminal proceedings - Public Ministry - victim - the principle of officialdom - Constitutional Court.

\section{INTRODUCCIÓN}

Desde hace un tiempo el Tribunal Constitucional chileno ha conocido una serie de casos en que personas víctimas de delitos, principalmente en el ámbito de las estafas, solicitan la declaración de inaplicabilidad por inconstitucionalidad de ciertas normas del Código Procesal Penal, entre otras razones, por ser contrarias al derecho fundamental a la acción penal que, argumentan, reconoce la Constitución en su artículo 83 inc. $2^{\circ}$. Las normas cuestionadas son aquellas que otorgan al Ministerio Público ciertas facultades, habitualmente calificadas como discrecionales, particularmente la de determinar la procedencia y oportunidad de la formalización de la investigación.

En ese contexto, el presente artículo pretende analizar el sentido de la participación de la víctima en el procedimiento penal, haciendo énfasis en el principio de oficialidad que rige el sistema chileno. La hipótesis que orienta este trabajo es que existiendo en Chile un modelo de persecución penal pública, la participación en el procedimiento que se le asigne al ofendido por el delito debe ser consistente con ese modelo. En este sentido, parece lógico atribuir a la víctima un rol de control y colaboración respecto de la persecución penal oficial, en este caso ejercida por el Ministerio Público, pero sin llegar a considerársele como portadora directa de la pretensión punitiva.

Importante es precisar que este trabajo está orientado exclusivamente al problema de la participación procesal del ofendido y no a derechos de otra índole, como los relativos a su protección o reparación, cuestiones que escapan de su objeto, y que además cuentan con un mayor consenso doctrinal.

El análisis del rol, y consecuentemente de las facultades, del ofendido por el delito en el proceso penal adquiere especial relevancia hoy que ha sido publicada la reforma constitucional que introduce, en el artículo $19 \mathrm{n}^{\circ}$ 3, la comúnmente denominada "defensoría de las víctimas", toda vez que parece importante que la instauración de tal institución esté precedida de una clarificación respecto del objeto de la participación del ofendido y especialmente de su forma de interacción con el órgano estatal encargado constitucionalmente de la persecución penal.

El trabajo está estructurado en tres secciones. En la primera, con el objeto de identificar algunas cuestiones controversiales en cuanto a la 
interpretación y aplicación de las normas que regulan el proceso penal, se reseña brevemente la evolución de la jurisprudencia del Tribunal Constitucional, la que da cuenta de varios puntos de tensión existente entre la actuación de los fiscales y las expectativas de las víctimas. En ella se muestra el giro que se produce luego de la primera sentencia que se pronuncia sobre la materia, destacándose las argumentaciones que se consideran pertinentes para este análisis.

En una segunda sección se aborda, desde un punto de vista doctrinario, los aspectos relativos al principio de oficialidad que rige el sistema procesal penal chileno y la participación de la víctima en el procedimiento. Teniendo como base los conceptos vertidos en las secciones anteriores, la última sección está destinada a desarrollar un análisis sobre algunas dificultades en la regulación del proceso penal chileno.

\section{1) El problema ante el Tribunal Constitucional}

Desde que el diecinueve de agosto de dos mil ocho el Tribunal Constitucional (en adelante el Tribunal) se pronunciara por primera vez, se ha dictado más de una decena de sentencias que abordan el problema que se suscita cuando la víctima se muestra en desacuerdo con el actuar del Ministerio Público y entiende que no cuenta con un mecanismo procesal para su canalización. Si bien no en todas las causas se pretende la inaplicabilidad de una misma norma, es posible seńalar que, en general, el problema tiene como denominador común la facultad privativa respecto de la procedencia y oportunidad de la formalización de la investigación que el Código Procesal Penal, en su artículo 230, ha entregado al Ministerio Público; ello teniendo presente que esa actuación procesal se constituye en requisito para que la víctima, en su calidad de querellante, pueda posteriormente hacer efectivo el derecho a optar al forzamiento de la acusación.

Ahora, a raíz de los distintos pronunciamientos del Tribunal en estas materias quedan en evidencia algunas controversias en cuanto a la interpretación y aplicación de algunas normas constitucionales y legales que regulan el proceso penal. En este sentido, en este trabajo el recurso a su jurisprudencia está orientado, más que a su análisis sistemático, a identificar algunas de esas controversias para su posterior análisis.

\section{(1.1) PRIMER PRONUNCIAMIENTO: SENTENCIA EN CAUSA ROL No 815-07}

El argumento central de este primer pronunciamiento, que va en la línea de reconocer a la víctima derechos irrestrictos en la persecución, sostiene que el ordenamiento jurídico chileno reconoce un derecho fundamental a la acción penal y que, consecuencialmente, cualquier forma 
de discrecionalidad por parte del Ministerio Público constituye una vulneración de ese derecho:

(...) "cabe concluir que cualquier razonamiento que conduzca a privar a la victima de su derecho a ejercer la acción penal, dando asi eficacia a su decisión de contar con un proceso jurisdiccional donde se le haga justicia, por causa de decisiones del Ministerio Público, ha de ser descartada, pues subordina el derecho de acceder a los tribunales a las decisiones del persecutor estatal, con lo cual se la priva, de esa forma, del derecho a la acción que le confiere el numeral $3^{\circ}$ del articulo 19 de la Carta Fundamental, en concordancia con el artículo 83 de la misma"1.

"Que en el sentido antes expuesto, entender la facultad del Ministerio Público de formalizar la investigación como una alternativa discrecional, en la cual no se puede interferir y de la que pueda derivar la decisión de no investigar y eventualmente archivar, aun cuando el afectado por el delito ha manifestado su voluntad de proseguir la persecución penal mediante la interposición de una querella, como ocurre en el caso sub lite, implica un acto de un órgano del Estado que produce como resultado evidente la negación de la tutela de los intereses penales de la víctima, la privación del derecho a la investigación del hecho delictivo y la imposibilidad de acceder a la jurisdicción, para que ésta resuelva el conflicto penal que la afecta, como lo ordena el artículo $7^{\circ}$ de la Constitución"2.

\section{(1.2) JURISPRUDENCIA POSTERIOR}

En sentencias posteriores el Tribunal, en cierto sentido, abandona su pronunciamiento inicial adoptando una posición de reconocimiento de las facultades privativas del Ministerio Público, pero haciendo énfasis en los diversos mecanismos que el Código Procesal Penal entrega a la víctima para el resguardo de sus intereses, los que permitirían contrarrestar las facultades del Ministerio Público. En efecto, en palabras del propio Tribunal, luego de ese primer pronunciamiento la jurisprudencia ha ido evolucionando desde esa posición original que consideraba que los derechos de la víctima estaban por sobre las facultades del fiscal, hasta una postura más atenuada, que establece ciertos criterios a través de los cuales se logra un equilibrio entre los derechos de esta y las facultades de aquel ${ }^{3}$.

1 Tribunal Constitucional. 19 de agosto de 2008. Rol No 815-2007. "Requerimiento de inaplicabilidad presentado por Patricio Rodrigo Meneses Farías respecto del artículo 230, inciso primero, del Código Procesal Penal”. Disponible en http://www.tribunalconstitucional. cl/index.php/sentencias/view/996 [fecha de visita 27 de mayo de 2011] considerando cuarto.

2 Tribunal Constitucional. Rol No 815-2007, considerando decimosegundo.

3 Tribunal Constitucional. 15 de abril de 2010. Rol No 1341-2009. "Requerimiento de inaplicabilidad por inconstitucionalidad de Raúl González Guzmán, respecto del artículo 248 del Código Procesal Penal". Disponible en http://www.tribunalconstitucional.cl/index. php/sentencias/view/1332 [fecha de visita 27 de mayo de 2011] considerando décimo. 
Esta etapa comienza con la sentencia en causa rol 1244, la que hace referencia a la existencia de distintos mecanismos judiciales y administrativos con que cuenta la víctima, destacando especialmente la función del juez de garantía en el proceso penal, en este caso, como garante de los derechos del ofendido en dicho proceso. El Tribunal hace hincapié en las facultades que durante la etapa de investigación le son conferidas al juez, así como su régimen de recursos, lo que permite un control jurisdiccional adecuado en favor del sujeto pasivo del delito, que cumple con el objeto de otorgar garantía de una investigación racional y justa. Sobre esta función del juez señala:

(...) "Tampoco puede prosperar una acción de inaplicabilidad en que, bajo la aparente imputación de inconstitucionalidad en la aplicación de determinado precepto legal en una gestión judicial pendiente, en realidad se pretende cuestionar la forma o modalidad en que determinadas autoridades han procedido en el cumplimiento de sus potestades privativas, cuando, precisamente, la ley ha atribuido expresamente al Juez de Garantía la tutela de los derechos fundamentales de los intervinientes en el proceso penal, todo ello sujeto a la formulación de los correspondientes recursos procesales en caso de una resolución adversa.

Así, a propósito de la víctima, el inciso primero del artículo $\sigma^{\circ}$ del Código Procesal Penal dispone que: 'Protección de la victima. El ministerio público estará obligado a velar por la protección de la víctima del delito en todas las etapas del procedimiento penal. Por su parte, el tribunal garantizará conforme a la ley la vigencia de sus derechos durante el procedimiento "'4.

Ahora, específicamente en relación al problema central -la exclusividad del Ministerio Público respecto de la decisión de formalizar la investigación- el Tribunal, a partir de la sentencia 1244, considera que la actuación regulada en el artículo 186 del Código Procesal Penal, relativa al control judicial anterior a la formalización, provee a la víctima de un mecanismo idóneo para cuestionar la negativa del fiscal a la formalización. Esta interpretación resulta novedosa toda vez que, en general, se ha entendido que esa norma contempla una garantía para el imputado y no para la víctima. Para el Tribunal la norma consagraría la posibilidad de una especie de forzamiento de la formalización, interpretación que había sido expresamente rechazada en la sentencia rol No 815-2007. Este argumento ha sido recurrente en la jurisprudencia del Tribunal:

Tribunal Constitucional. 2 de junio de 2009. Rol No 1244- 2008. "Requerimiento de inaplicabilidad por inconstitucionalidad de Cosmética Vegetal S.A. respecto de los artículos 229, 230, inciso primero, y 237, inciso antepenúltimo, del Código Procesal Penal”. Disponible en http://www.tribunalconstitucional.cl/wp/descargar_sentencia.php?id=1153 [fecha de visita 30 de agosto de 2011] considerando vigésimo. 
"Que, teniendo en consideración que el derecho constitucional a ejercer la acción penal pública se hace efectivo mediante la correspondiente acusación y que según los artículos 260 y 261 del Código Procesal Penal, ello requiere que previamente se haya formalizado el procedimiento, es dable concluir que el artículo 186 de ese cuerpo legal empodera al juez, en tanto responsable de cautelar los derechos de la victima y querellante, para controlar a solicitud de este interviniente la prerrogativa que otorga el articulo 230 a los fiscales del Ministerio Público, consistente en determinar la oportunidad de formalizar la investigación";

"Que, como puede observarse, es el juez de garantía el responsable, en último término, de cautelar, en forma igualitaria, los derechos de los diversos intervinientes en el proceso penal, entre ellos, los de la víctima y querellante, quien requiere hoy al Tribunal Constitucional.

Tal responsabilidad exige, sin duda, una interpretación del artículo 186 del Código Procesal Penal que no reduzca exclusivamente al imputado las facultades que en él se contienen. Por el contrario, una interpretación amplia que incluya tanto al imputado como al ofendido por el delito o víctima es la única que permitiría respetar íntegramente el espíritu y la letra del artículo 83 de la Constitución, en relación con sus artículos 19, No $3^{\circ}$-que asegura la igualdad en el ejercicio de los derechos-, y $5^{\circ}$, que obliga a todos los órganos del Estado a respetar y promover los derechos asegurados en ella, así como aquellos consagrados en tratados internacionales ratificados por Chile y vigentes"6.

Fundado, entre otras consideraciones, en esta interpretación del artículo 186, el Tribunal ha negado declarar la inaplicabilidad de las normas del Código Procesal Penal, como el artículo 230, en el entendido que dicha interpretación le confiere una lectura conforme a la Carta Fundamental.

\section{(1.3) UN HITO: SENTENCIA EN CAUSA ROL No 1341-09}

Si bien la sentencia en causa Rol No 1341-09 no constituye un cambio en la línea jurisprudencial del Tribunal -el que luego de la primera sentencia ha mantenido su criterio contrario a la declaración de inapli-

5 Tribunal Constitucional. 3 de noviembre de 2009. Rol N 1380-2009. "Requerimiento de inaplicabilidad por inconstitucionalidad de Carlos Jordán Ortiz respecto de los artículos 230, inciso primero, y 186, ambos del Código Procesal Penal”. Disponible en http://www. tribunalconstitucional.cl/index.php/sentencias/view/1255 [fecha de visita 27 de mayo de 2011] considerando decimoséptimo.

6 Tribunal Constitucional. 5 de octubre de 2010. Rol No 1484-2009, cinco de octubre de 2010. "Acción de inaplicabilidad por inconstitucionalidad del Servicio de Vivienda y Urbanización Metropolitano respecto de los artículos 186, 229, 230 y 231 del Código Procesal Penal". Disponible en http://www.tribunalconstitucional.cl/index.php/sentencias/ view/1575 [fecha de visita 27 de mayo de 2011] considerando vigesimosegundo. 
cabilidad en esta materia fundado entre otras consideraciones en la interpretación amplia del artículo 186- este pronunciamiento destaca porque en él se tratan aspectos como el de los principios que rigen el sistema procesal penal, particularmente respecto de la vigencia del principio de legalidad procesal y del principio de oficialidad. De esta forma, la sentencia hace referencia al carácter público de la persecución penal y, en ese contexto, a los derechos que tiene la víctima en el proceso:

"Que el hecho de que se trate de una persecución penal pública y no privada tiene una relevancia fundamental al momento de evaluar la legitimidad del rol que se le asigna al ofendido por el delito dentro del respectivo modelo de persecución penal.

En el nuevo modelo diseñado por la Reforma Procesal Penal, se ha justificado abundantemente la necesidad de que el Ministerio Público pueda actuar con discrecionalidad, ya que con ello se beneficia al sistema de manera completa e integra. Ello no obsta, como se analizará más adelante, a que también se reconozcan derechos a la víctima dentro del proceso y a que exista control sobre su actuación"7.

"Que el hecho de que la persecución penal provenga de los órganos del Estado, explica que la victima no pueda ocupar el mismo lugar ni el mismo rol que ocupa el Ministerio Público en el sistema"8.

A partir de los pronunciamientos del Tribunal es posible iniciar una reflexión sobre ciertos aspectos del procedimiento penal, como el sentido de la persecución oficial y el rol que le cabe a la víctima en ese contexto, y en términos concretos sobre ciertas normas del Código Procesal Penal chileno que están en el centro de esta problemática.

\section{2) SOBRE EL PRINCIPIO DE OFICIALIDAD Y LA PARTICIPACIÓN DE LOS PARTICULARES EN EL PROCESO}

El problema que se ha presentado ante la jurisdicción constitucional radica en la colisión que se produce entre las facultades del Ministerio Público, por una parte, y las pretensiones de la víctima por otra. Las presentaciones realizadas ante el Tribunal dan cuenta de una disconformidad de los ofendidos por el delito con la actuación del persecutor oficial, y de su aspiración a que se les reconozca un derecho que les permita imponerse frente a las actuaciones del Ministerio Público que consideran erradas.

Para enfrentar situaciones como estas, en principio es necesario determinar el rol que le corresponde a cada uno de estos intervinientes en el sistema, toda vez que la atribución amplia e imprecisa de derechos y

Tribunal Constitucional. Rol No 1341-2009, considerando trigésimo tercero.

Tribunal Constitucional. Rol No 1341-2009, considerando septuagésimo quinto. 
facultades para ambos solo puede derivar en su recurrente colisión. Aho$\mathrm{ra}$, el primer tópico a analizar en este intento es el relativo al sentido del principio de oficialidad en la persecución penal.

\section{(2.1) EL PRINCIPIO DE OFICIALIDAD}

Como señalan Horvitz y López, el principio de oficialidad constituye la regla general en el nuevo sistema procesal penal chileno, cuestión que no significa novedad respecto del sistema establecido en el antiguo código. La Constitución dispone que el Ministerio Público dirigirá en forma exclusiva la investigación de los hechos constitutivos de delito y en su caso ejercerá la acción penal pública en la forma prevista por la ley, disposición que a su vez es recogida por el artículo 1 de su Ley Orgánica Constitucional? .

Para los mismos autores el principio de oficialidad expresa la idea de persecución penal pública de los delitos, esto es, la noción de que estos pueden y deben ser perseguidos por el Estado de oficio, sin consideración a la voluntad del ofendido ni de ninguna otra persona. Su antítesis teórica es el principio dispositivo en sentido estricto, que implica la disponibilidad de las partes sobre el interés privado y la conveniencia o no de acudir al órgano jurisdiccional pretendiendo su satisfacción ${ }^{10}$.

Por su parte Maier seńala que una de las características básicas del sistema actual de administración de justicia penal reside en la atribución de la persecución penal al Estado lo que, comparado con su prestación de justicia en otras materias, significa una ampliación de su campo de acción, al atribuir al Estado un interés en la realización del Derecho penal, interés que, ordinariamente, excluye de la cuestión penal a todo otro interés real en el conflicto social que conforma su base ${ }^{11}$.

Para el autor argentino constituyen una excepción al monopolio del Estado en la persecución penal los delitos de acción privada, no así la incorporación de otro interés a la persecución penal pública, por ejemplo el representado por la víctima o sus sustitutos y que opera juntamente con el representado por el Ministerio Público o por adhesión a él. Señala que la incorporación de este interés privado no desplaza ni excluye la persecución penal del Estado, siempre principal y determinante para la solución del caso ${ }^{12}$.

\footnotetext{
9 Horvitz, María Inés; López, Julián (2002) Derecho procesal penal chileno. Santiago: Editorial Jurídica de Chile, Tomo I, p. 38.

HoRvitz / López (2002) 36.

11 Maier, Julio (2004) Derecho procesal penal. 2a edición, 3a reimpresión. Buenos Aires: Editores del Puerto, Tomo I Fundamentos, p. 825.

12 En este sentido MaIER (2004) 827-828.
} 
Para Roxin, el fundamento del principio de oficialidad es el interés público en que los hechos punibles no queden sin persecución, ya que muchas veces los particulares no pueden o no están dispuestos a ejercer la acción por sí mismos, o pueden, por temor a una venganza, prescindir de una denuncia penal ${ }^{13}$.

Por su parte, analizando la finalidad de la acusación, Pérez Gil señala que esta tiene por objetivo directo la tutela del interés público consistente en la activación de los mecanismos para el debido enjuiciamiento y, en su caso, condena de las conductas reputadas punibles, dirigido todo ello a servir de sustitutivo a la autodefensa prohibida por el Estado. Estando dirigida a satisfacer un interés público, no abarcaría dentro de sí la inclusión de intereses privados, siempre extravagantes a la misión que viene a desempeñarse a través de ella. Para el autor, quien ejercita la pretensión penal no pide nada para sí, ni para nadie en especial, sino que realiza una actividad que va dirigida mediatamente en beneficio de la colectividad ${ }^{14,15}$.

Así, el principio de oficialidad, en razón del interés público prevalente en la persecución de los delitos, constituye un eje de la persecución penal en el modelo que ha seguido Chile, y, aunque su vigencia no excluya necesariamente la participación de los particulares en el proceso, es preciso analizar el alcance de dicha participación, toda vez que esta, por razones prácticas y de principio, que se analizarán más adelante, no debiera desvirtuar ni sustituir el rol estatal.

\section{(2.2) EL INTERÉS DE LA VÍCTIMA}

Para analizar la participación de la víctima en el proceso penal parece apropiado tratar, como un primer elemento, cuál es el interés defendido por la víctima. En este tópico Pérez Gil señala que el delito afecta la esfera jurídica de un sujeto, determinando el nacimiento de específicos intereses materiales que se podrán defender en el proceso penal, pero que han de ser distinguidos frente al interés procesal en el enjuiciamiento, que es el objeto del interés público. Se trata de intereses individualizables y singularizables subjetivamente, que pertenecen exclusivamente a la víctima. En este sentido, la defensa del interés propio del ofendido que se pretende realizar mediante el ejercicio de la acusación particular no se ejecuta desde la objetividad e imparcialidad, sino que tiene el sesgo propio de un

13 Roxin, Claus (2000) Derecho procesal penal. Traducción de la 25a edición alemana de G. Córdoba y D. Pastor revisada por J. Maier. Buenos Aires: Editores del Puerto, p. 83.

14 En este sentido Pérez Gil, Julio (1998) La acusación popular. Granada: Editorial Comares, p. 306-309.

15 También plantea el autor que el que la acusación tenga como finalidad el satisfacer un interés público implica que dicha función deba ser satisfecha desde la imparcialidad, en tanto el interés público requiere indefectiblemente el enjuiciamiento solo de los hechos respecto de los que fundadamente se afirme que han conculcado la norma material. Pérez GIL (1998) 308. 
sujeto que reclama derechos cuya titularidad afirma. Postula el autor que la implicación emotiva de los sujetos afectados por el delito en el ejercicio de la acusación no es imprescindible y, en ocasiones, no es siquiera deseable, en tanto el interés que les mueve no es el mero enjuiciamiento, sino el de la búsqueda explícita de una condena que sirva de base al resarcimiento de los daños y perjuicios sufridos. Señala que aun cuando la actuación del acusador particular puede tener como consecuencia la defensa del interés general, en el entendido que el interés privado puede servir de manera refleja a su satisfacción, la acusación particular, necesariamente parcial e interesada, no debe ser considerada apta para su tutela ${ }^{16}$.

Para Pérez Gil el proceso penal no debe ser entendido como una forma de canalización de la venganza sino como la respuesta debida por el Estado a todos los ciudadanos, ofendidos o no, para la satisfacción del interés público ${ }^{17}$. Así también señala Hirsch que se oponen a la participación activa del ofendido en el procedimiento penal las ideas básicas del procedimiento oficial, entre ellas el hecho de que se debe lograr una objetivación del procedimiento penal en la parte que corresponde al acusador. Su tarea se debe dirigir a la obtención de la verdad hacia ambas direcciones, no solo hacia la condena ${ }^{18,19,20 .}$

Otra parte de la doctrina, en cambio, ve en la participación de los particulares en el proceso penal mediante en el ejercicio del ius puniendi

16 En este sentido Pérez GIL (1998) 357-359.

17 Pérez Gil (1998) 359.

18 Hirsch, Hans (1992) "Acerca de la posición de la víctima en el Derecho penal y en el Derecho procesal penal". En Maier, Julio (compilador): De los delitos y de las víctimas. Buenos Aires: Editorial Ad-Hoc, pp. 91-128, p.120.

19 A su vez Roxin, comentando la legislación alemana, señala que la valoración político-jurídica de la $O p f e r s c h u t z G$, en el marco de la discusión sobre la intervención del ofendido en el procedimiento, es discrepante. Por un lado, la ampliación conveniente de la autorización para la acción adhesiva es un adelanto frente a la absurda regulación anterior. Pero por otro, no se puede desconocer que el fortalecimiento de las posiciones del acusador adhesivo y del ofendido se presta para facilitar la primacía de la necesidad de venganza del afectado sobre el interés general de la resocialización. Este retroceso político-criminal se podría haber evitado si se hubiera relegado al ofendido a un papel moderado, en atención a la sanción del autor, y, en su lugar, se hubiera asignado una importancia mayor a su interés de reparación, que, de todos modos, ocupa un lugar primordial para él. Roxin (2000) 524-525.

20 Maier rechaza las objeciones a la participación del ofendido que le atribuyen motivos ilegítimos como la venganza, señala que, con la única investigación empírica que conoce, se puede decir que la figura de la víctima vengativa, al menos con exclusión de los delitos de mayor gravedad y por medio del procedimiento judicial, no existe o existe en sus justos límites. Reivindica que la víctima tiene derecho a la disculpa del agresor y a que él repare el dańo causado por su acción; también tiene derecho a esperar la aplicación racional de la ley penal por parte de los órganos judiciales y a colaborar, para ello, en la búsqueda de la verdad, paradigma actual de la administración de justicia. Seńala que la ansiedad por perseguir, por encima de esos límites, es rara y según su experiencia sería catalogada como patológica; además es neutralizada perfectamente por las reglas del procedimiento. MaIer, Julio (1992) "La víctima y el sistema penal". En Maier, Julio (compilador): De los delitos y de las víctimas. Buenos Aires: Editorial Ad-Hoc, pp. 183-249, p.214-215. 
estatal un paliativo a la prohibición de la autotutela, el ejercicio de un derecho cívico o un modo de intervención de la sociedad en la realización del Derecho penal ${ }^{21}$. Así por ejemplo Moreno y Cortés, a propósito de la amplísima participación de los particulares en el proceso penal español, señalan que "esta solución legislativa, que ha merecido fundadas críticas, permite sin embargo conjugar todos los intereses posibles que inciden en un procedimiento penal, pues da entrada a la víctima para que pueda instar la sanción de la conducta que le ha dańado, a cualquier ciudadano que pretenda intervenir acusando, en la medida en que forma parte de la sociedad agredida por el delito, y no descuida la protección de la sociedad, de modo que corresponsabiliza en alguna medida a todos los componentes de la sociedad y al propio tiempo sirve de control a la actuación del Estado" 22 .

\section{(2.3) ALCANCES DE LA PARTICIPACIÓN DE LA VÍCTIMA}

Independientemente del interés que se le atribuya doctrinariamente a la víctima, o de la valoración que se haga de su participación en el proceso, en la práctica en el derecho comparado existen diversos mecanismos, que, con distinto grado de profundidad, incorporan al ofendido en el procedimiento penal, introduciendo matices al monopolio del Ministerio Público en la acción penal. En general, la principal motivación para ello es que estos sirvan como control de la actividad estatal, y particularmente como una forma de asegurar la aplicación del principio de legalidad u obligatoriedad en materia procesal penal, en aquellos ordenamientos regidos por él ${ }^{23}, 24$. Desde otro punto de vista, también es posible justificar la importancia de la participación del ofendido en el procedimiento penal como la necesaria forma de controlar la discrecionalidad técnica, inherente al actuar del persecutor oficial ${ }^{25}$.

21 Ferreiro, Xulio (2005) La Victima en el proceso penal. Madrid: editorial La Ley, p. 203.

22 Moreno Catena, Víctor.; Cortés Domínguez, Valentín (2004) Derecho Procesal Penal. Valencia: Tirant lo Blanch, p. 101.

23 Explica Maier que frente a la decisión de oficializar la persecución penal, como regla general, se ha impuesto el principio de legalidad a los órganos del Ministerio Público y a los funcionarios de la policía, ello implica el deber de promover la persecución penal ante la noticia de un hecho punible en procura de la decisión judicial, y que una vez promovida no se pueda suspender, interrumpir o hacer cesar, sino por el modo y la forma previstos en la ley procesal. MAIER (2004) 828.

24 Caianello señala que a pesar de los eventuales inconvenientes que pueda conllevar el otorgar al privado un poder de acción concurrente o subsidiario, este puede constituir un instrumento para la aplicación del principio de obligatoriedad, compensando la inercia del órgano público. El rol del privado es ser un instrumento de control y estímulo en la promoción de la pretensión punitiva. En este sentido Caianello, Michele (2003) Poteri dei privati nell' esercizio dell' azione penale. Turín: Giappichelli, p. 75.

25 Sobre la discrecionalidad técnica, explica Díez Picazo que al igual que cualquier otra operación de aplicación del derecho, el ejercicio de la acción penal se caracteriza por la presencia 
Para Ferrajoli "es obvio que si la publicidad de la acusación conlleva la obligatoriedad de su ejercicio para los órganos públicos competentes, no implica en modo alguno una titularidad exclusiva, siendo perfectamente compatibles con el modelo teórico acusatorio formas autónomas, libres y subsidiarias de acción popular, dirigidas a integrar la acción del Ministerio Público en defensa de los derechos e intereses, individuales o colectivos, ofendidos por el delito; a solicitar y, donde sea necesario, a remediar la inercia culpable de los órganos públicos; a permitir la participación y el control popular del ejercicio de la acción penal e indirectamente de la función judicial en su conjunto" 26 .

A su vez, Fix-Zamudio cuestiona la existencia de un monopolio oficial en la legislación mexicana señalando que el ofendido debe ser reconocido como parte subsidiaria o accesoria del Ministerio Público en el mismo proceso penal, lo que no le hace partícipe de la función pública de la acusación ni favorece la venganza privada sino que exclusivamente lo constituye como auxiliar del proceso, al solicitar la intervención del juzgador cuando el Ministerio Público no cumple con sus funciones esenciales o lo hace de manera indebida ${ }^{27}$.

En definitiva, es posible señalar que en doctrina se apoya la participación de los privados, y particularmente de la víctima, en el procedimiento oficial, pero principalmente atribuyéndole a esta un carácter auxiliar, accesorio, entendiendo que dicha participación está destinada a controlar el ejercicio de la persecución por el órgano estatal.

Ahora, en términos concretos, Maier señala que existen dos modos principales de incorporar al ofendido al procedimiento penal oficial. El primero es concederle derechos autónomos para acusar al lado del Ministerio Público, en calidad de querellante conjunto. La segunda posibilidad indicada por el autor es permitirle su intervención solo en la medida en la que colabore con la persecución penal oficial y la controle, por ello llamado querellante adhesivo. Señala que esta última forma supone la accesoriedad de la persecución penal del ofendido, la que depende en último término, de la persecución penal oficial. En razón de esta accesoriedad

de un ámbito de discrecionalidad, ya que presupone una operación de valoración de hechos e interpretación de normas en virtud de la cual se decide si se está técnicamente en condiciones de ejercer la acción penal y cuál es el modo más adecuado de hacerlo. A este respecto puede hablarse de una discrecionalidad técnica o interpretativa como elemento inherente al ejercicio de la acción penal. Señala que la discrecionalidad técnica suscita un inevitable problema jurídico-político: ¿cómo se ejerce y qué mecanismos hay para controlarla? DíEz Picazo, Luis (2000) El poder de acusar. Ministerio Fiscal y Constitucionalismo. Barcelona: Ariel, p. 15-16.

26 Ferrajoli, Luigi (1998). Derecho y razón. Teoría del garantismo penal. Madrid: Editorial Trotta, p. 569-570.

27 En este sentido Fix - Zamudio, Héctor (2004). Función constitucional del Ministerio Público. Primera reimpresión. México D.F: Universidad Nacional Autónoma de México, p. 108. 
requiere siempre la pendencia de la acción pública, y por ello es que al querellante adhesivo no se le permite acusar o recurrir la decisión final autónomamente. Cuando tales actos son producidos por el querellante adhesivo en presencia de un comportamiento procesal contrario del $\mathrm{Mi}$ nisterio Público, desencadenan mecanismos de control judicial o jerárqui$\cos ^{28,29}$.

Respecto de la valoración de las alternativas planteadas, Maier postula que si el sistema penal conserva la pena estatal y la persecución penal pública, la solución de la querella adhesiva es la única compatible con el sistema y, también, la más adecuada a la hora de evitar que la intervención de la supuesta víctima en el procedimiento penal represente un menosprecio (desequilibrio) intolerable para los derechos defensivos del imputado o, cuando menos una carga demasiado pesada para él. Señala que la primera afirmación se justifica, pues permitir, en ese sistema, plena autonomía a la acusación privada, significa, en ciertas circunstancias, convertir la persecución penal pública en privada, el procedimiento oficial en algo igual o semejante a un juicio por delito de acción privada, contraviniendo, por lo tanto, la decisión legislativa de que corresponde la persecución penal estatal. Para el autor la representación privada de un interés estatal no es una figura adecuada y solo constituiría un juego de palabras, a ella le faltaría la objetividad y legalidad que se requiere de la actividad desarrollada por órganos del Estado ${ }^{30}$.

Por último en este punto, la conclusión de Pérez Gil quien señala que el proceso penal tiene que ser necesariamente útil a la defensa de los legítimos derechos de la víctima, pero que la actividad de esta habrá de incardinarse normativamente desde la simultánea contemplación de los objetivos, necesidades y garantías inherentes al proceso penal. Expresa que teniendo presente el extendido y compartido deseo de tutelar los intereses de la víctima, no se puede obviar que el ejercicio de la pretensión penal exige una serenidad, objetividad y sujeción a criterios igualitarios que solo son imaginables desde la históricamente consolidada institucionalización de la respuesta a las conductas criminales ${ }^{31}$.

Maier (1992) 235.

Maier explica que el querellante adhesivo solo puede adherir a la acusación del Ministerio Público, señalar sus vicios para que sean corregidos, objetarla porque no incluye a algún imputado u omite alguna circunstancia, para que ella sea ampliada convenientemente, u objetar el sobreseimiento o clausura del procedimiento pedidos por el Ministerio Público, requiriendo que se lo obligue a acusar. El tribunal competente para el procedimiento intermedio efectúa el control de legalidad de los requerimientos conclusivos de la instrucción preliminar, efectuados por el Ministerio Público y decide el caso. El Proyecto de CCP Modelo Iberoamérica, propone de forma principal la solución de la querella por adhesión. MAIER (1992) 235-236.

30 MAIER (1992) 236-237.

31 PÉrez GiL (1998) 359. 


\section{3) LA PROBLEMÁTICA EN LA CONFIGURACIÓN NORMATIVA CHILENA ACTUAL}

Atendiendo a los conflictos planteados ante el Tribunal Constitucional y considerando los planteamientos doctrinarios presentados, parece posible señalar que la legislación chilena no establece un sistema apropiado de participación de la víctima en el proceso penal oficial. Es posible pensar que no existe una definición clara del rol que le corresponde a la víctima, que en definitiva delimite su participación respecto de la del $\mathrm{Mi}$ nisterio Público, particularmente teniendo presente la naturaleza oficial del proceso penal chileno.

De acuerdo a lo planteado por la doctrina, es posible, y para muchos incluso deseable, integrar a la víctima al proceso penal, pero para mantener la coherencia con el principio de oficialidad que rige el sistema, ello debiera hacerse denotando que la función de la víctima es de colaboración y control del actuar del Ministerio Público, pero en caso alguno puede significar que esta llegue a sustituirle. Ahora, como se ha señalado, en el ordenamiento jurídico chileno no queda claramente establecida esa diferenciación de roles, lo que contribuye a la generación del conflicto. Por ello parece importante recordar aquí el pronunciamiento del Tribunal Constitucional que hace referencia a la naturaleza pública de la persecución penal, asignándole a esta característica relevancia fundamental al momento de evaluar la legitimidad del rol que se le asigna al ofendido dentro del modelo de persecución penal, precisando que la víctima no puede ocupar el mismo lugar, ni el mismo rol que ocupa el Ministerio Público en el sistema ${ }^{32}$.

Con esta premisa, parece necesario reflexionar respecto de tres normas específicas del sistema: la norma constitucional del artículo 83 que, a primera lectura, otorga amplias facultades tanto al Ministerio Público como a la víctima; la norma del Código Procesal Penal que autoriza el forzamiento de la acusación y las normas que conceden al fiscal la definición sobre la procedencia y oportunidad de la formalización.

\section{(3.1) El ARTÍCUlo 83 DE LA CONSTITUCIÓN}

El artículo 83 de la Constitución, sin duda, es una norma de interpretación compleja, ya que si bien parece en su inciso $1^{\circ}$ consagrar el principio de oficialidad, su inciso $2^{\circ}$ introduce de manera poco clara a la víctima en el proceso oficial. Un indicio de esta dificultad de interpretación aparece en las apreciaciones de Piedrabuena, quien señala que "Si bien el Art. 83 inciso $2^{\circ}$ (sic) le entrega al Ministerio Público la atribu-

32 Tribunal Constitucional. Rol No 1341-2009, considerando septuagésimo quinto. 
ción de ejercer la acción penal pública, esta no es una atribución exclusiva puesto que el inciso $2^{\circ}$ del mismo precepto dispone que "el ofendido por el delito y las demás personas que determine la ley podrán ejercer igualmente la acción penal", de modo que no puede haber impedimentos en el derecho o en los hechos de parte de ningún organismo para limitar los derechos de quienes ejercen la acción penal pública, particularmente las víctimas de delitos. La norma constitucional mencionada deja en claro que la víctima tiene derechos distintos a los fiscales, porque de lo contrario, no tendría sentido legislar para que pudieran ejercer igualmente la acción penal"33.

Ahora, es posible pensar que la redacción del inciso $2^{\circ}$ del artículo 83, a diferencia de la apreciación de Piedrabuena, no es clara en distinguir entre la naturaleza de los derechos de la víctima y las facultades del Ministerio Público, pero, tal como lo señala el autor, carecería de sentido legislar para entregarle iguales atribuciones. Por ello, si se pretende sostener la consagración del principio de oficialidad en el sistema procesal penal chileno, necesario es concluir que no es posible realizar una interpretación en orden a reconocer a la víctima un derecho autónomo a la acción penal, equivalente a la función del Ministerio Público. La interpretación de la norma debiera ir en el sentido de afirmar el rol accesorio de la víctima.

Para Bordalí la interpretación sistemática del artículo 83 de la Constitución y las normas pertinentes del Código Procesal Penal conduce a entender que el derecho de la víctima es a participar de la acción penal, participación que se concreta a través de la querella y de la acusación, cuando esta última sea procedente, conforme a la dirección de la investigación que ha llevado el Ministerio Público. Seńala que cuando se introdujo este órgano en la Constitución de 1980 se optó por transar entre el modelo original del Ejecutivo, en que la persecución penal era preeminentemente pública y las modificaciones introducidas por el legislador que buscaban dar mayor participación a las víctimas. El resultado de ello sería un modelo que se resume en participación por parte de la víctima en la actividad persecutoria penal que debe llevar adelante el Ministerio Público, donde participación no es lo mismo que titularidad del enjuiciamiento criminal ${ }^{34}$.

33 Piedrabuena, Guillermo (2009) "Cómo proteger mejor los intereses de las víctimas y de esta manera contribuir a la disminución de la delincuencia”. Revista Chilena de Derecho, vol. 36 No 3, pp. 671-677, p. 673-674.

34 Bordalí, Andrés (2008). "No hay ejercicio del derecho fundamental de acción en el proceso penal. Sentencia del Tribunal Constitucional que declaró inaplicable el artículo 230 del Código Procesal Penal". Revista de Derecho Universidad Austral de Chile, vol. XXI, pp. 205250 , p. $249-250$. 


\section{(3.2) EL CONTROL JUDICIAL ANTERIOR A LA FORMALIZACIÓN}

En un segundo orden de ideas, respecto al conflicto específico de la procedencia de la formalización -actuación que se ha entendido como privativa del Ministerio Público- resulta novedosa la interpretación realizada por el Tribunal Constitucional en el sentido de permitir, a través del artículo 186 del Código Procesal Penal, que la víctima pueda instar a ella ante el juez de garantía.

Esta interpretación del artículo 186, que innova respecto del sentido que tradicionalmente se le ha asignado a la norma, cual es reconocerle al imputado la posibilidad de instar a la formalización, tiene como inconveniente el permitir que la víctima pueda alterar en alguna medida la estrategia del Ministerio Público, que constitucionalmente está encargado de dirigir en forma exclusiva la investigación de los hechos constitutivos de delitos $^{35}$.

Ahora, esta aplicación del artículo 186 a favor de las pretensiones de la víctima parece comprensible en razón del contexto de amplia participación que ha configurado la Constitución y el Código Procesal Penal. Porque, desde su punto de vista, el negarle al querellante toda atribución en este sentido parece contradictorio con la posibilidad de presentar querella, pues resulta extraño que el derecho de la víctima se limite a la presentación de la querella, y que desde allí la progresión efectiva del proceso esté entregada privativamente a la decisión del Ministerio Público.

Parece difícil explicar que la víctima no pueda simplemente instar a una actuación esencial para la prosecución del procedimiento como es la formalización de la investigación, y sin embargo, como se analizará inmediatamente, la ley le reconozca facultades para anteponerse a la decisión del fiscal y acusar autónomamente. Existe una contradicción entre la protección absoluta del interés de la víctima respecto de la acusación y el desconocimiento, también absoluto, de este en relación a la formalización, en especial teniendo presente que esta actuación, indudablemente, constituye un requisito de la primera. Porque lo que definitivamente no parece apropiado es la posibilidad acerca de la que razona el Tribunal Constitucional, en cuanto a la procedencia del forzamiento de la acusación respecto de una investigación no formalizada ${ }^{36}$, esta posibilidad parece poco

35 Se señala que la formalización es una decisión eminentemente estratégica para el fiscal, quien para determinar su conveniencia u oportunidad debe evaluar aspectos como el estado de avance de la investigación, el hecho de existir un imputado individualizado, la necesidad de solicitar diligencias o la procedencia de medidas que puedan afectar derechos constitucionales, la necesidad de mantener la investigación en un estado de reserva mayor, etc. Duce, Mauricio; Riego, Cristián (2007). Proceso Penal. Santiago: Editorial Jurídica de Chile, p. 226.

36 En este sentido Tribunal Constitucional, 13 de julio de 2010. Rol No 1394-2009. "Requerimiento de inaplicabilidad por inconstitucionalidad de Pedro Alejandro Ruiz Prado res- 
plausible tanto por la interpretación literal de las normas involucradas y, particularmente, considerando que la formalización es una actuación que se establece como una garantía para el imputado y por ende constituye un requisito esencial para la acusación, conforme al principio de congruencia consagrado en el Código Procesal Penal. En efecto, en sentencia posterior, el Tribunal se pronuncia en sentido contrario a la interpretación anterior, argumentando precisamente la importancia del principio de congruencia, que resguarda, en palabras del Tribunal, "una medular garantía del enjuiciamiento para el inculpado", y que tiene por objeto evitar que este pudiere ser sorprendido con imputaciones respecto de las cuales no ha podido preparar prueba de descargo, ni ejercer cabalmente sus posibilidades de defensa ${ }^{37}$.

En las condiciones actuales del sistema procesal penal chileno, el reconocer a la víctima, en su calidad de querellante, la facultad de instar a la formalización parece conciliable con el rol accesorio en el proceso propuesto en este trabajo, en la medida que esta no hace más que requerir un pronunciamiento del tribunal que finalmente resuelva sobre su procedencia, manteniendo bajo responsabilidad del Ministerio Público la realización de la actuación. Además, debe considerarse que en sí misma la formalización no implica una afectación directa para los derechos del imputado, desde que, como se señaló, es una actuación eminentemente garantista ${ }^{38}$.

Además, en ciertos casos, como los conocidos por el Tribunal Constitucional, cuando existe una querella, la formalización parece absolutamente necesaria para el transcurso lógico del proceso, ya que esta obliga al fiscal a investigar, investigación que luego debe concluir formalmente, ya sea con la acusación o a través del sobreseimiento o la decisión de no perseverar. Pues bien, cualquiera de estas acciones supone una investigación formalizada. Como se señaló, no es posible acusar cuando la investigación no ha sido formalizada, y tampoco parece lógico pretender el sobreseimiento o decidir no perseverar, pues sin formalización no existe determinación respecto de los hechos a los cuales le serían aplicables tales decisiones.

pecto de la letra c) y del inciso final del artículo 248 del Código Procesal Penal”. Disponible en http://www.tribunalconstitucional.cl/index.php/sentencias/view/1468 [fecha de visita 27 de mayo de 2011] considerandos cuadragésimo primero y cuadragésimo segundo.

37 Tribunal Constitucional. 31 de agosto de 2010. Rol No 1542-2009. "Acción de inaplicabilidad por inconstitucionalidad de Juez Titular del Juzgado de Garantía de Castro respecto del inciso final del artículo 259 del Código Procesal Penal”. Disponible en http://www. tribunalconstitucional.cl/wp/descargar_sentencia.php?id=1506 [fecha de visita 30 de agosto de 2011] considerandos quinto y sexto.

38 Señalan Duce y Riego que la formalización tiene fundamentalmente propósitos de garantía: permite al imputado el conocimiento cierto de la imputación, implica el comienzo, con carácter de necesaria, de la actividad de la defensa y significa que el fiscal queda limitado por los hechos incluidos en los cargos formulados, no pudiendo ampliarlos sorpresivamente en la acusación. Duce / Riego (2007) 220. 


\section{(3.3) EL FORZAMIENTO DE LA ACUSACIÓN}

Por último, en cuanto al mecanismo de forzamiento de la acusación consagrado en el Código Procesal Penal es posible señalar que este no parece acorde con el rol accesorio que se entiende debiera tener la víctima en el contexto del procedimiento oficial. Como se expusiera anteriormente, la figura del querellante adhesivo es la que resulta más compatible con el principio de oficialidad. En este sentido, el querellante adhesivo si bien puede instar el forzamiento de la acusación, de obtener una resolución favorable esta obliga al Ministerio Público a acusar. En cambio, en el caso chileno el forzamiento de la acusación tiene como efecto que la acción es ejercida exclusivamente por el particular, lo que puede ser interpretado como una asunción por parte de la víctima de la acción penal pública o como la transformación de la acción penal pública en privada, cuestión que parece contradictoria con la lógica del sistema.

Para Horvitz cuando opera el forzamiento de la acusación, el querellante detenta el control absoluto y exclusivo de la acción penal pública en juicio. La privatización de la persecución penal pública es total y excede el marco de la satisfacción del interés privado para constituirse en el vehículo de aplicación de una pena que cumple funciones públicas. Senala que aunque podría argumentarse que el querellante cumple aquí un control importante sobre las actuaciones ilegales o arbitrarias del Ministerio Público, le parece que para ello el control judicial y administrativo sería suficiente ${ }^{39}$.

Como se señala en doctrina, la norma que consagra el forzamiento de la acusación en el proceso penal chileno tiene su antecedente en una similar de la Ordenanza Procesal Penal alemana, parágrafos 172-177 $\mathrm{StPO}^{40}$. Ahora, según lo expuesto por Pérez Gil, el "Procedimiento para compeler al ejercicio de la acción penal" alemán (Klageerzwingungsverfahren), configura para el ofendido una facultad de control judicial sobre las decisiones del fiscal denegatorias de la acusación, por lo que no es una modalidad de ejercicio directo de la pretensión penal que venga a quebrar el monopolio del fiscal, sino que permite a los particulares agraviados solicitar a un órgano jurisdiccional que compela al Ministerio Fiscal a desplegar sus facultades de persecución. Señala que dado que el Klageerzwingungsverfahren no es propiamente acusación, el solicitante no puede realizar una calificación del delito, ni puede imponer los términos en que la acusación deba realizarse ${ }^{41}$.

Horvitz / López (2002) 296.

Horvitz / López (2002) 588

PÉrez GIL (1998) 733. 
Efectivamente, en esta fase de acusación, un control por parte de la víctima, que fuera compatible con el principio de oficialidad, solo debiera implicar que ante el desacuerdo con la decisión del fiscal, esta pudiera desencadenar un pronunciamiento judicial que, de serle favorable, forzara al Ministerio Público a acusar. No resulta apropiado que ante la aprensión de que el fiscal forzado a acusar actuara posteriormente de manera negligente, se opte por privatizar la acción, cuando ciertamente es posible conjurar ese peligro a través de medidas de tipo administrativas al interior del Ministerio Público.

Si bien se conocen mecanismos en el derecho comparado en que la víctima puede llegar a ejercer independientemente la acción penal, transformándose esta en privada, esta posibilidad está circunscrita a cierto tipo de delitos. Bovino expone la posibilidad de conversión de la acción penal pública en privada contemplada en la legislación de Costa Rica, Guatemala y El Salvador, en los que, en general, procede la conversión respecto de los delitos que requieren de instancia particular, de aquellos en que no existe un interés público gravemente comprometido y en los delitos contra la propiedad ${ }^{42}$.

Una conversión de la acción, limitada al tipo de delitos señalados, sería una posibilidad interesante para mejorar el sistema chileno, toda vez que permitiría a la víctima perseverar por sí misma en la persecución penal. Ahora, la acción convertida necesariamente debiera sujetarse a los principios que rigen el ejercicio de la acción pública, particularmente el principio de objetividad, por ello una institución como esta debiera complementarse con alguna forma de control del Ministerio Público respecto del actuar del acusador particular, invirtiendo el rol original de ambos intervinientes. En este sentido, Maier propone que en cierto tipo de delitos, en que la supuesta víctima se halla en óptimas condiciones para ejercer la persecución penal, debiera ser posible, por decisión judicial o interna de la fiscalía, delegarle el ejercicio de la acción penal pública, pero bajo su supervisión. Para el autor esta forma de colaboración significaría una manera propia de confiarle a la víctima, con ciertas limitaciones, la representación de la pretensión punitiva estatal. La supervisión estaría orientada a evitar arbitrariedades en el ejercicio del poder de perseguir penalmente y a sujetar al acusador privado a la legalidad y objetividad que preside, en principio, la persecución penal oficial ${ }^{43,44}$.

42 En este sentido Bovino, Alberto (2005). "La participación de la víctima en el procedimiento penal". Revista Jurídica Universidad Católica de Santiago de Guayaquil, edición 19, pp. 1-39 Disponible en http://www.revistajuridicaonline.com/index.php [fecha de visita 27 de mayo de 2011] p. 24.

43 En este sentido Maier, Julio (2003) Derecho procesal penal. Buenos Aires: Editores del Puerto. Tomo II, p. 627-628.

44 Un interesante análisis del principio de objetividad es planteado por Duce y Riego, quienes señalan que este puede significar tres tipos de cuestiones para el Ministerio Público: primero 
En definitiva, es posible pensar en una configuración legislativa que permita que la víctima se constituya en un colaborador o controlador de la actividad oficial en la persecución de los delitos de acción penal pública, pero ello no puede significar una sustitución de la actividad del persecutor estatal, tanto por una cuestión de coherencia, de conveniencia práctica, como de los principios que se resguardan a través de la persecución oficial. El asumir como equivalentes los derechos de la víctima y las facultades del Ministerio Público solo puede tener como consecuencia un conflicto insoluble en razón de dicha paridad. Pero más aún, debe tenerse presente que el procedimiento penal debe compatibilizar el resguardo de los derechos de todos sus intervinientes, y en particular del imputado. Porque no se puede olvidar que, como lo señala Díez Picazo, la acción penal es un arma formidable pues implica la activación de un mecanismo que puede conducir a la restricción aflictiva de la libertad y la propiedad de las personas, además del carácter infamante ínsito en la condena penal, y que incluso cuando el proceso penal termina con la absolución implica una dura prueba para el imputado, en términos psíquicos, económicos e, incluso, de estima social ${ }^{45}$.

\section{CONCLUSIÓN}

Tradicionalmente el ordenamiento procesal penal chileno ha estado regido por el principio de oficialidad, conforme al cual la persecución penal de los delitos le corresponde al Estado, el que debe realizarla de oficio, sin consideración a la voluntad del ofendido ni de ninguna otra persona.

El principio de oficialidad ha de ser el contexto que permita evaluar la legitimidad de la intervención de la víctima en el proceso penal y por lo tanto al diseñar mecanismos de participación debe resguardarse que ellos no desvirtúen esta característica basal del sistema. En este sentido en doctrina se plantea que la fórmula adecuada para incorporar a la víctima al proceso es la de constituirla como querellante adhesivo, figura que se

implica que deba chequear hipótesis fácticas de exclusión o atenuación de responsabilidad plausibles y serias argumentadas por la defensa, manifestación que denominan "deber de profesionalismo del Ministerio Público en la investigación". En segundo lugar implica un deber de lealtad para con la defensa, que se traduce en que el Ministerio Público no debe esconder información disponible que puede favorecer a esta y en su deber de mostrar sus cartas en forma oportuna para que la defensa pueda prepararse adecuadamente. Finalmente, el principio impone al Ministerio Público el deber de actuar de buena fe durante todo el desarrollo del procedimiento, evitando que las reglas de un juego justo sean vulneradas, debiendo siempre resguardar que se mantenga vigente la posibilidad de que la defensa pueda actuar de manera eficaz en favor de sus intereses. Duce / Riego (2007) 145-146.

Díez Picazo (2000) 11. 
caracteriza por cumplir un rol de colaboración y control respecto de la persecución penal oficial, y por lo tanto accesoria a esta.

En el ordenamiento procesal penal chileno no existe claridad respecto de esta diferenciación de roles, situación que agudiza el conflicto entre víctimas y Ministerio Público respecto de los derechos y facultades de cada uno. La falta de definición acerca del rol de la víctima en el proceso, y la pretensión de mantener la dirección oficial de la persecución conjuntamente con una participación prácticamente equivalente de la víctima, ha provocado que, por una parte se obviara asignarle a esta facultades en una fase determinante del proceso cual es la formalización, lo que limita sus posibilidades de instar efectivamente a la persecución por parte del fiscal (la querella por sí sola no siempre basta), y en cambio se extralimitara su participación a través de la figura del "forzamiento de la acusación", que no es otra cosa que la privatización de la acción.

Frente a esta situación, parece comprensible la jurisprudencia del Tribunal Constitucional que, favoreciendo la participación del ofendido, ha interpretado de una manera más extensiva la figura del artículo 186 del Código Procesal Penal, reconociendo a las víctimas la facultad para compeler, a través de una declaración judicial, a la formalización, ya que esta actuación constituye un elemento esencial para llevar adelante la persecución penal.

Ahora, conforme a lo argumentado es posible señalar que el sistema chileno adolece de una importante inconsistencia al contemplar la institución del forzamiento de la acusación, la que no se adecua al carácter oficial del proceso penal, oficialidad que tiene por objeto el respeto de principios como la legalidad y objetividad, que han de ser exigibles del persecutor estatal.

\section{BibLiOgRAFÍA}

Bordalí, Andrés (2008). "No hay ejercicio del derecho fundamental de acción en el proceso penal. Sentencia del Tribunal Constitucional que declaró inaplicable el artículo 230 del Código Procesal Penal". Revista de Derecho Universidad Austral de Chile, vol. XXI, pp. 205-250.

Bovino, Alberto (2005). "La participación de la víctima en el procedimiento penal". Revista Jurídica Universidad Católica de Santiago de Guayaquil, edición 19, pp. 1-39 Disponible en http:// www.revistajuridicaonline.com/index.php [fecha de visita 27 de mayo de 2011].

Caianello, Michele (2003) Poteri dei privati nell' esercizio dell' azione penale. Turín: Giappichelli.

Díez Picazo, Luis (2000) El poder de acusar. Ministerio Fiscal y Constitucionalismo. Barcelona: Ariel. 
Duce, Mauricio; Riego, Cristián (2007). Proceso Penal. Santiago: Editorial Jurídica de Chile.

Hirsch, Hans (1992) "Acerca de la posición de la víctima en el Derecho penal y en el Derecho procesal penal”. En Maier, Julio (compilador): De los delitos y de las víctimas. Buenos Aires: Editorial Ad-Hoc, pp. 91-128.

Horvitz, María; López, Julián (2002) Derecho procesal penal chileno. Santiago: Editorial Jurídica de Chile, tomo I.

Ferrajoli, Luigi (1998) Derecho y razón. Teoría del garantismo penal. Madrid: Editorial Trotta.

Ferreiro, Xulio (2005) La víctima en el proceso penal. Madrid: Editorial La Ley.

Fix-Zamudio, Héctor (2004) Función constitucional del Ministerio Público. Primera reimpresión. México D.F: Universidad Nacional Autónoma de México.

Maier, Julio (2004) Derecho procesal penal. 2a edición, $3^{a}$ reimpresión. Buenos Aires: Editores del Puerto, Tomo I Fundamentos.

(2003) Derecho procesal penal. Buenos Aires: Editores del Puerto. Tomo II Parte general, Sujetos procesales.

(1992) "La víctima y el sistema penal". En Maier, Julio (compilador): De los delitos y de las víctimas. Buenos Aires: Editorial Ad-Hoc, pp. 183-249.

Moreno Catena, Víctor.; Cortés Domínguez, Valentín (2004) Derecho Procesal Penal. Valencia: Tirant lo Blanch.

Pérez Gil, Julio (1998) La acusación popular. Granada: Editorial Comares.

Piedrabuena, Guillermo (2009) "Cómo proteger mejor los intereses de las víctimas y de esta manera contribuir a la disminución de la delincuencia”. Revista Chilena de Derecho, vol. 36 No 3, pp. 671-677.

Roxin, Claus (2000) Derecho procesal penal. Traducción de la 25a edición alemana de G. Córdoba y D. Pastor revisada por J. Maier. Buenos Aires: Editores del Puerto. 